\title{
The Evolutionary Emergence of Vertebrates From Among Their Spineless Relatives
}

\author{
Philip C. J. Donoghue • Mark A. Purnell
}

Published online: 5 May 2009

(C) Springer Science + Business Media, LLC 2009

\begin{abstract}
The evolutionary origin of vertebrates has been debated ad nauseam by anatomists, paleontologists, embryologists, and physiologists, but it is only now that molecular phylogenetics is providing a more rigorous framework for the placement of vertebrates among their invertebrate relatives that we can begin to arrive at concrete conclusions concerning the nature of ancient ancestors and the sequence in which characteristic anatomical features were acquired. Vertebrates tunicates and cephalochordates together comprise the chordate phylum, which along with echinoderms and hemichordates constitute the deuterostomes. The origin of vertebrates and of jawed vertebrates is characterized by a doubling of the vertebrate genome, leading to hypotheses that this genomic event drove organismal macroevolution. However, this perspective of evolutionary history, based on living organisms alone, is an artifact. Phylogenetic trees that integrate fossil vertebrates among their living relatives demonstrate the gradual and piecemeal assembly of the gnathostome body plan. Unfortunately, it has not been possible to demonstrate gradual assembly of the vertebrate body plan. This is not because vertebrates are irreducibly complex but because many of the characters that distinguish vertebrates from invertebrates are embryological and cellular and, therefore, inherently unfossilizable.
\end{abstract}

P. C. J. Donoghue $(\bowtie)$

Department of Earth Sciences, University of Bristol,

Wills Memorial Building, Queen's Road,

Bristol BS8 1RJ, UK

e-mail: phil.donoghue@bristol.ac.uk

M. A. Purnell

Department of Geology, University of Leicester,

University Road,

Leicester LE1 7RH, UK
Keywords Evolution - Origin - Deuterostome Echinoderm $\cdot$ Hemichordate $\cdot$ Chordate $\cdot$ Vertebrate

Humans and all other back-boned animals - plus a few others that have no bone at all - comprise the vertebrates. Vertebrates are a clade, meaning that all members of the group have evolved from a common ancestor that they all share. This means that the deeper parts of our evolutionary history are entwined with the origin of the clade, and it should thus come as no surprise to discover, therefore, that the origin of vertebrates has been the subject of intense debate since the earliest days of evolutionary research. In his book Before the backbone, Henry Gee recounts a great number of theories that, over the last century and a half, have invoked almost every other major living animal group as the ancestors of vertebrates (Gee 1996). Mercifully, there is now much less equivocation over the relationships of vertebrates to their living relatives, none of which are thought of as being ancestral. Rather, vertebrates and their nearest kin - the invertebrate chordates, the hemichordates and the echinoderms - are more correctly perceived as living representatives of distinct genealogical lineages that separated one from another deep in geological time. It is the aim of many paleontologists, comparative anatomists, embryologists, and molecular biologists to uncover the genealogical relationships of these animals - their family tree - and to test this tree with evidence that bears on the question of how these distinct organismal designs. Explanations of the emerging evolutionary pattern range from traditional Darwinian gradualistic evolution to those that invoke explosive diversifications (seized upon by creationists and intelligent designers as evidence for irreducible complexity (Meyer 2004a, b) but which are actually consistent with natural causal mechanisms (McLennan 
2008)). Whatever the pattern and processes, a holistic understanding of the origin and diversification of vertebrates can only be obtained by a holistic approach, integrating all relevant strands of evidence into a framework of evolutionary relationships established on the basis of the only universal characteristics shared by all organisms: molecular sequence data.

\section{Phylogenetic Framework-How Vertebrates Are Related to Their Nearest Invertebrate Kin}

Establishing a phylogenetic framework of relationships among organisms is an essential prerequisite to uncovering the patterns and mechanisms of evolution. Traditionally, the evidence to support evolutionary trees has been derived from analysis of skeletal, muscular, and nervous systems, development and embryology, and cell characteristics. Invariably, these different aspects of organismal biology were studied in isolation and resulted in conflicting ideas of animal relationships that have been difficult to resolve (Jenner and Schram 1999). However, at the deepest levels in the genealogy of animals, such as the splits between phyla and groups of phyla, embryological and cell characters have held sway, not least because there are no skeletal characters shared between phyla. Most animals are bilaterally symmetrical_or show evidence of a bilateral ancestry in their embryology-and fall into one of two major groups: the protostomes (first mouths) or the deuterostomes (second mouths), the names of which betray the embryological characters on which they were defined ${ }^{1}$. Vertebrates belong to the chordate phylum and along with hemichordates (acorn worms and pterobranchs) and echinoderms (sea lilies, star fish, sea urchins, sea cucumbers) have long been considered deuterostomes. Whether there are additional deuterostomes has been the subject of long-running debate. Classically, chaetognaths (arrow worms) and lophophorates - bryozoans (moss animals) and brachiopods (lamp shells) - have been considered deuterostomes, based on similarities of the larvae from which the more familiar adults develop, but this is no longer the prevailing view. Such instability stems from the fact that,

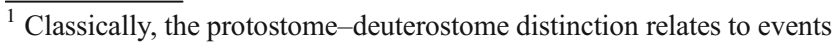
in early embryology. The fertilized cell undergoes repeated rounds of binary division (cleavage) to produce a ball of tens to hundreds of cells that are rearranged into distinct germ layers surrounding a central space (gastrulation). Following this, the embryo invaginates to the point where half of what was the outside is completely enclosed within, leaving only a small hole. In protostomes, this hole is the earliest manifestation of the mouth, while in deuterostomes it becomes the anus. It should be noted however that these are classical caricatures of the embryology and it has long been known that there are deviant members of Protostomia and Deuterostomia, perhaps betraying that there are still things we do not know about the genealogy of animals (Raineri 2006).
}

while features shared by phyla may well reflect their kinship, the absence of features is more difficult to interpret (Donoghue and Purnell 2009; Jenner 2004). It may indicate that in one clade the characters in question were never present, providing evidence against a close evolutionary relationship with clades that possess them, or it could be that the characters were originally inherited by both clades from their common ancestor but were subsequently lost in one. Indeed, even what appear to be shared similarities between phyla can be unreliable because they may reflect evolutionary convergence and independent acquisition rather than common ancestry. Because of these problems and because the universe of available data had largely been exhausted, attempts to decipher the relationships between animal phyla could not reach a consensus and it is hard to see how this situation would have changed were it not for the availability of genetic sequence data. Analysis of this rapidly expanding molecular dataset has provided a robust and essentially independent test of the theories of evolutionary relationships previously derived from anatomical and developmental data.

Perhaps the most surprising result of the molecular phylogenetic revolution has been that the majority of the classical groupings of animals, and their evolutionary relationships, have withstood testing, even in the face of ever-greater molecular datasets, representing ever-more lineages (e.g., Bourlat et al. 2008; Dunn et al. 2008). The composition of some major clades and the details of their relationships have, however, been the subject of dramatic change. For example, the lophophorates and chaetognaths have been excised from the deuterostomes and are now recognized to be protostomes (although their precise relations within the protostomes remain an open question). The residual deuterostomes have also been rearranged: hemichordates and chordates were considered more closely related to one another than to echinoderms, but there is now very strong molecular support for the Ambulacraria grouping of hemichordates and echinoderms, to the exclusion of chordates (Fig. 1). Xenoturbella, a worm-like animal of hitherto enigmatic affinity, is recognized as a fourth very minor phylum of just two species that is more closely related to ambulacrarians than chordates (Bourlat et al. 2006), collectively comprising the clade Xenambulacraria (Bourlat et al. 2008).

With this increasingly reliable phylogenetic framework in place, it is now possible to turn to the question of how the major groups of deuterostomes emerged through evolutionary history. This is not a trivial challenge: the deuterostomes may be a small grouping of just four phyla, but the body plans that characterize the phyla are as anatomically disparate as any. Tradition would have us start our discussion with the last common ancestor of all deuterostomes and move up the evolutionary tree considering each subsequent branch in turn. However, as well as being overly deterministic, perpetuating the erroneous teleological impression 


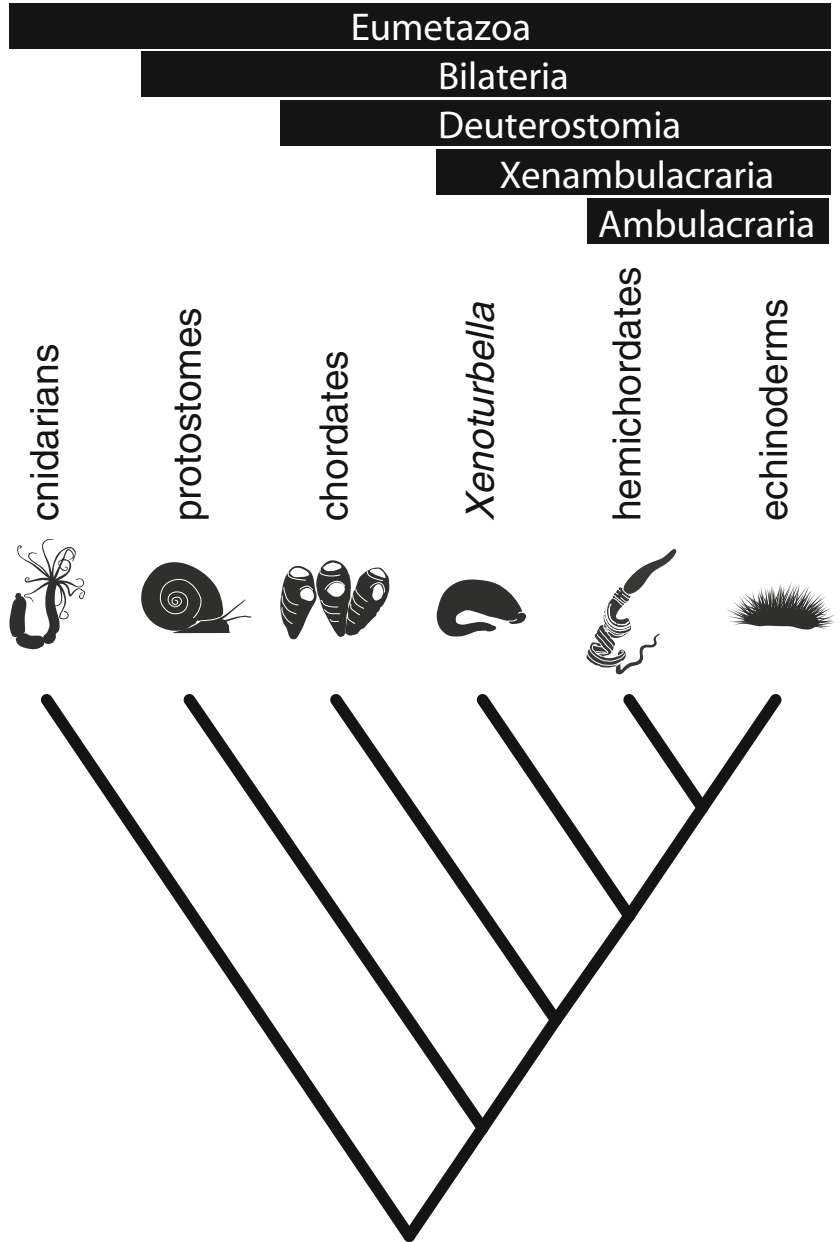

Fig. 1 The interrelationships of the deuterostome phyla within the context of Metazoa. Primarily based upon Dunn et al. (2008) and Bourlat et al. (2008)

that evolution progressed towards vertebrates this would not reflect certainties concerning knowledge of relationships and the sequence of character evolution, which are far better resolved within phyla than between phyla. So we will take a different route here, starting with our own familiar branch, the vertebrates, and working backwards to more distant and unfamiliar relatives, attempting to describe events in evolutionary history that are well constrained, through to those that are not so well constrained.

\section{The Emergence and Evolution of Vertebrates}

Jawed Vertebrates-More Than Just a Pretty Smile

It may come as a surprise to learn that more than $99 \%$ of living vertebrates fall within one subgroup of the vertebrate clade, the gnathostomes (Fig. 2). Named after one of their most conspicuous anatomical characters, jaws, gnathostomes are much more than just a pretty smile, and the list of features that distinguishes them from their living jawless relatives contains what might be generally, but incorrectly, considered as distinctive attributes of the vertebrate body plan. This includes teeth and a mineralized internal skeleton forming a braincase, jaws (and, in fish, gill supports), a backbone, trunk, and appendages. These appendages (arms and/or legs or fins) are paired and occur in the shoulder and pelvic regions. The different tissues of the mineralized skeletonbone, cartilage, dentine, and enamel-are also unique, among living animals, to gnathostomes. Features of the brain and inner ear also distinguish gnathostomes, together with a good many other characters that are too detailed to recount here (for more details, see Donoghue et al. 2000; Janvier 2001). In fact, the number of anatomical characters that distinguish living jawed from jawless vertebrates is even greater than the complementary suite of features that distinguish vertebrates from invertebrates (see below).

\section{Vertebrates Get Ahead}

A vast number of characters distinguish vertebrates from their nearest invertebrate relatives among chordates. Some of the more obvious features include a distinct anatomical head with a distinct brain, paired sensory organs, together
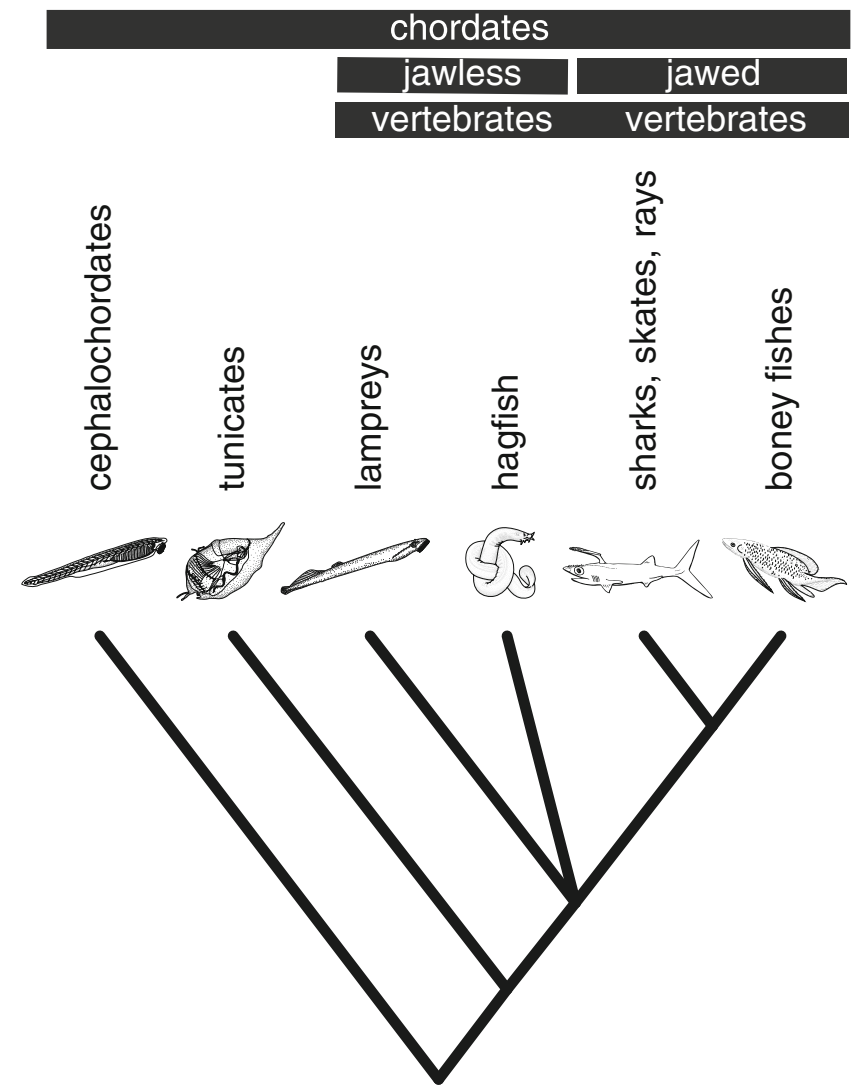

Fig. 2 The interrelationships of the principal groups of living chordates and vertebrates. Primarily based upon Delsuc et al. (2006) 
with a number of specialized cell types that are responsible for the development and function of the nervous system and skeleton. The majority of these vertebrate-specific characters can be accounted for by a couple of embryological innovations that have long been thought exclusive to vertebrates, but for which evidence of evolutionary rudiments has grudgingly been found in the invertebrate chordates (Donoghue et al. 2008). These innovations are neurogenic placodes and neural crest cells (Gans and Northcutt 1983).

During development, neurogenic placodes give rise to the sensory organs of the central and peripheral nervous systems, including the eyes, nasal organs, inner ear, and the lateral line system of fishes. Neural crest cells are a specialized population of migratory cells which behave like stem cells in that they have the potential to differentiate into a broad spectrum of specialized cell types, such as specialized neurons and glia of the nervous system, pigment cells, and cells of the dermis (Le Douarin and Kalcheim 1999). It is also from neural crest cells that the gnathostome's dermal and pharyngeal bone, cartilage, and dentine develop. Because most of these anatomical characters are exclusive to vertebrates, it has been thought that neurogenic placodes and neural crest cells were the key innovations that underpinned a rapid evolutionary emergence of vertebrates. This is now known to be an oversimplification: certain sense organs in tunicates, for example, develop from placodes in a manner comparable to their vertebrate counterparts, and their development is regulated by a common suite of molecular factors (Mazet et al. 2005). Similarly, some tunicates also possess a migratory cell population that emerges during the early development of the nervous system, and these cells differentiate into pigment cells - a characteristic derivative of neural crest-utilizing an equivalent repertoire of genes (Jeffery 2006; Jeffery et al. 2004). Nevertheless, the diversity and functionality of sensory organs and neural crest cell derivatives in invertebrate chordates are far less than in their vertebrate counterparts, and without doubt the evolution of the potentiality of neurogenic placodes and neural crest was key to the emergence of vertebrates (Donoghue et al. 2008).

The Emergence of Vertebrates from Their Spineless Relatives

Understanding what distinguished vertebrates from other animals is only part of the picture. We also need to know the details of how they fit into the Tree of Life. Here, once again, molecular phylogenetics has weighed heavily upon classical interpretations. Generally, new data have confirmed the monophyly of vertebrates and chordates (but see Lartillot and Philippe 2008), but in other areas of the deuterostome tree decades of dogma have been overturned. In particular, debate over the relationships among the principal lineages of living vertebrates has become polarized into two conflicting hypotheses, each derived from different kinds of data. Molecular analyses indicate that the hagfishes and lampreys comprise a clade to the exclusion of jawed vertebrates (Bourlat et al. 2006; Delarbre et al. 2002; Delsuc et al. 2006; Mallatt and Winchell 2007), while morphological datasets support a clade of lampreys and jawed vertebrates to the exclusion of hagfishes (Donoghue et al. 2000; Donoghue and Smith 2001; Forey 1995; Gess et al. 2006; Janvier 1981, 1996; Løvtrup 1977). Whichever hypothesis turns out to be correct, it is unlikely to have major consequences for understanding the broader picture of vertebrate and gnathostome origins.

Perhaps the biggest surprise of recent molecular revisions to the chordate tree is the recognition that the peculiar tunicates (sea squirts) and not cephalochordates (amphioxus) are the closest invertebrate relatives of the vertebrates (Delsuc et al. 2006; Heimberg et al. 2008; Fig. 2). While this conclusion, at first quite shocking, is now generally accepted, it has very few implications for what we understand of the nature of common ancestor of all chordates. Under either scenario, this ancestor must have been an amphioxus-like organism because segmented muscles and paired pharyngeal gill slits are characters general to deuterostomes, and a notochord is a character general to chordates (i.e., because they all share these characters, the most parsimonious interpretation is that they all inherited them from their common ancestor).

Genetic Drivers of Vertebrate and Gnathostome Innovation

Strikingly, the burst of embryological and anatomical innovation at the origin of vertebrates and gnathostomes seems to correspond to radical events in the evolution of their genomes. At some stage, along the lineage leading to living vertebrates after its separation from tunicates, the vertebrate genome was duplicated, at once doubling the repertoire of coding and noncoding DNA. Similarly, at some point after the living jawless vertebrates branched off, a second duplication took place prior to the appearance of the last common ancestor of living gnathostomes. In each case of duplication, one gene set was available to maintain its existing functions, but a matching set was free to evolve without compromising the original function of the genes. Thus, new gene functions could emerge to regulate the development of organisms and their organs, leading rapidly to innovation (see McLennan 2008 for discussion of duplication and cooption in evolution generally). There is abundant evidence that this occurred: (1) all living vertebrates can be shown to possess, or to have possessed, two copies of the genes possessed by invertebrate chordates; (2) all living gnathostomes can be shown to possess, or to have possessed, at least four copies (Holland et al. 1994), and, in comparison to preduplication relatives, lineages arising postduplication exhibit an expansion of 
function of these genes in regulating development. Of course, not all duplicate genes have been retained, but there is good evidence for the selective retention of genes that are essential to the anatomical and developmental innovations of vertebrates and gnathostomes. For instance, of the duplicate genes retained, there is a particular pattern of retention of genes that encode protein products associated with the extracellular matrices that are essential for skeletal development (Huxley-Jones et al. 2007) and of genes implicated in neural crest patterning and differentiation (Martinez-Morales et al. 2007).

There has been much debate about the tempo and mode of organismal evolution associated with genome duplication. Some have argued for a direct causal linkage such that genome duplication drives a geologically instantaneous burst of evolution (Sidow 1996; Wagner et al. 2003), while others have argued for a more permissive role wherein genome duplication is a necessary prerequisite of organismal evolution, but the effect on organismal evolution unfolds gradually over a protracted period of time (Prohaska and Stadler 2004). The principal evidence marshaled in support of the evolutionary burst hypothesis is the observation that living vertebrates and gnathostomes are distinguished from living invertebrate chordates and jawless vertebrates, respectively, by very large inventories of anatomical and developmental characters - surely only genome duplication can explain the emergence of so many characters in concert?
What the Fossils Say

So far, we have discussed only living gnathostomes, vertebrates, and chordates, but this provides an extremely incomplete perspective on vertebrate organismal evolution because current vertebrate diversity is only a small subset of the vertebrates that have ever lived. Many major branches from the vertebrate Tree of Life have been extinguished, and we are familiar with very many of them and the information that they provide on the pattern, timing, and tempo of evolution. For instance, dinosaurs record the gradual assembly of the body plan of modern birds (Padian and Chiappe 1998) and there is a comparably rich record of synapsid reptiles that record the gradual assembly of the body plan of modern mammals (Kemp 2007; Angielczyk 2009). No one, therefore, would attempt to explain the emergence of birds or mammals directly from reptilian ancestors in a geologically instantaneous event. The same is true of gnathostome origins.

Interleaved in the Tree of Life, between living jawless and jawed vertebrates, is a parade of long-dead and in some cases bizarre-looking fish that records clearly how gnathostome characters were acquired over a period of at least 80 million years (Fig. 3). Somewhere around the base of the lineage connecting living jawed vertebrates to the split from the hagfish and lampreys, is a number of fossils which lack a mineralized skeleton and are hard to place precisely (Bardack 1991; Bardack and Richardson 1977; Bardack
Fig. 3 The interrelationships of living and extinct jawless and jawed vertebrates. Primarily based upon Donoghue et al. (2000) and Donoghue and Smith (2001)

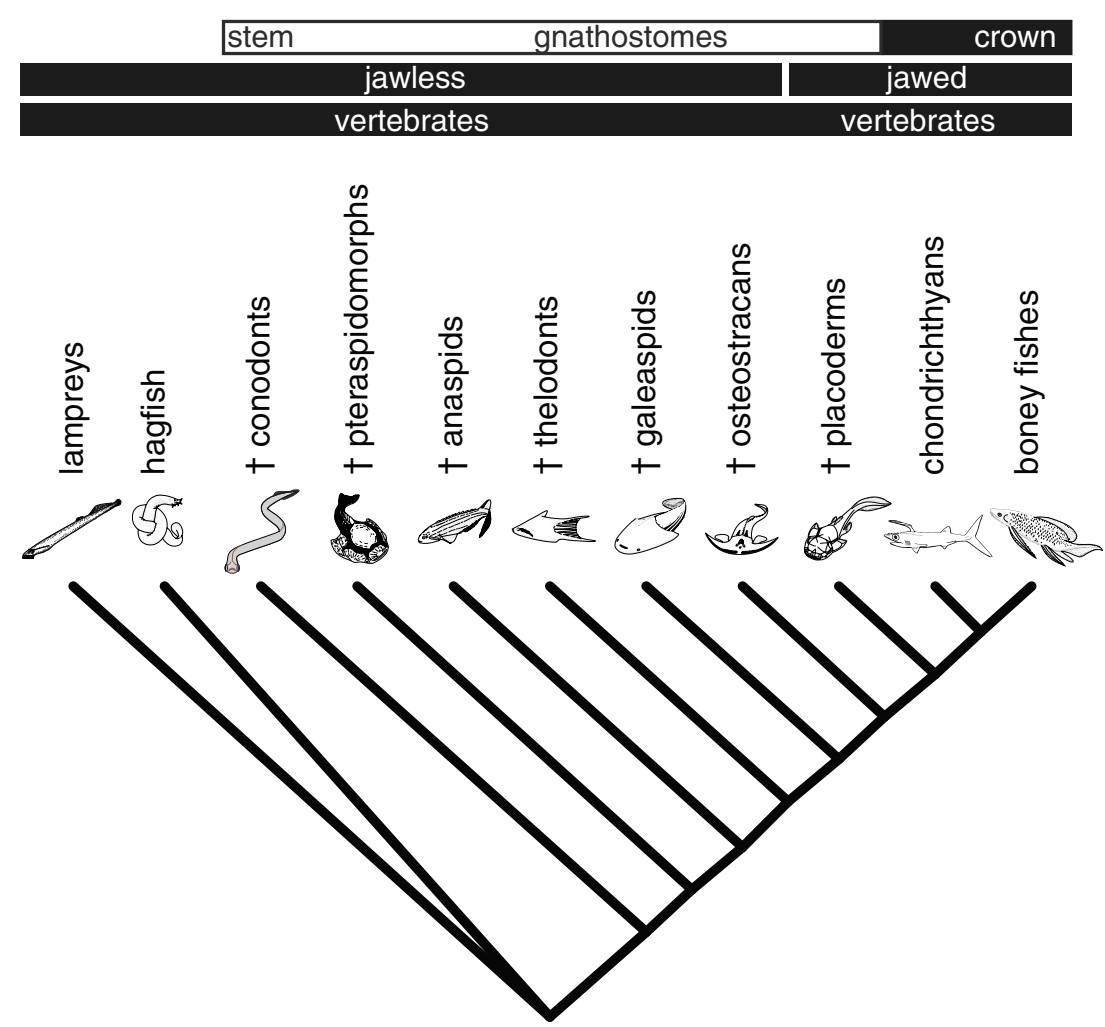


and Zangerl 1968; Chang et al. 2006; Gess et al. 2006; Janvier and Lund 1983; Shu 2003; Shu et al. 1999, 2003a; Sweet and Donoghue 2001). They sit among the jawless fishes or between them and gnathostomes (they are not shown in Fig. 3). Above these non-mineralized vertebrates the conodont branch splits away. These small eel-shaped animals were like lampreys and hagfishes in almost every way except that they also possessed a mineralized skeletona complex raptorial array of teeth composed of enamel and dentine. The next to branch off were the pteraspidomorphs, characterized by an extensive armor plating, encasing the entire body from tip to tail, composed of acellular bone, dentine, and an enamel-like tissue (enameloid). This group also contains the first vertebrates to show evidence of semicircular canals of the inner ear that are distinct from the roof of the utriculus. Next to diverge were the anaspids, a small group of jawless vertebrates possessing the "gnathostome" characters of conodonts and pteraspidomorphs, plus a distinct stomach, unseen in hagfishes, lampreys, conodonts, or pteraspidomorphs. Thelodonts are even more closely related to gnathostomes, and this is betrayed by their possession, in addition to a mineralized dermal skeleton and a differentiated stomach, of tooth-like structures associated with their gills. Galeaspids, the next branch up the tree, are the first vertebrates to possess a mineralized braincase, albeit one composed entirely of cartilage, and they are perhaps also the first vertebrates in which the inner ear is connected directly to the exterior via an endolymphatic duct. Osteostracans are the last group of jawless vertebrates to diverge from the gnathostome lineage and they possess still further "gnathostome" characters, including slit-shaped gills and bony supports encapsulating their eyes, as well as an asymmetrical tail with a long upper lobe like that of sharks and paired pectoral - but no pelvic - fins. Their skeleton contains types of bone that are unknown in earlier forms: perichondral bone in the braincase and fin skeleton and dermal bone comprising much of the external bony armor. The last extinct branch to diverge from the jawless vertebrate-gnathostome lineage is the placoderms. They possess, from the list of characters otherwise known only in living gnathostomes, a mineralized jointed gill skeleton, pelvic fins, a mineralized vertebral column, mineralized fin supports (radials), and jaws. Of the few remaining "gnathostome" characters, the only one that can be verified as exclusive to living jawed vertebrates (because if it was present in fossils it has the potential to be recognized) is the particular position of the attachment of one of the muscles that controls movement of the eye.

Very clearly, the assembly of what, based on living animals, would be considered as a distinctive gnathostome body plan is anything but instantaneous. Extinct intermediates of living jawless and jawed vertebrates demonstrate its gradual assembly and, if anything, the effect of genome duplication on organismal evolution cannot have been anything more than a permissive factor. The earliest jawed vertebrates were certainly not "hopeful monsters" and, once again, they are demonstrably not irreducibly complex. Nevertheless, the acquisition of a jaw, with the benefit of hindsight, can be identified as a key innovation underpinning the diversification of jawed vertebrates because, combined with the locomotory advances afforded by the acquisition of a backbone and paired fins, it allowed jawed vertebrates to occupy new feeding niches and ecological habitats and to disperse into geographic regions that were previously not open to vertebrates.

\section{The Emergence of Vertebrates}

The example of the holistic perspective on the emergence of jawed vertebrates demonstrates that, at least in this instance, a coincidence of genome duplication and organismal evolution should not lead directly to the conclusion that one caused the other. The same pattern of gradual assembly can be demonstrated for the emergence of teleosts from their actinopterygian relatives (Donoghue and Purnell 2005), dispelling any notion of rapid organismal evolution or an explosive radiation (Wagner et al. 2003).

Unfortunately, fossils do not allow us to make similar observations concerning the assembly of the characters that distinguish living vertebrates from their nearest invertebrate relatives. We simply cannot tell from the fossil record whether the suite of vertebrate innovations evolved rapidly or gradually because the majority of innovations are embryological and cell characteristics, and these are inherently unfossilizable. Consequently, even recognizing correctly the fossils that might fill the gaps between amphioxus, tunicates, and hagfish is problematic. There are a few Cambrian contenders but it is difficult to determine whether these are genuine fossil vertebrates from which most vertebrate characteristics have rotted away or fossils that belong in a more basal position in the tree, with invertebrate chordates (e.g., Cathaymyrus and Metaspriggina; Conway Morris 2008; Shu et al. 1996a).

Nevertheless, from the example of gnathostomes, we should be skeptical of a direct causal linkage between genome duplication and organismal evolution - or any other causal mechanism of instantaneous evolution - in explaining the emergence of vertebrates. Rather, it is more likely that vertebrate characteristics emerged over a long and protracted episode of gradual change, but the organisms that record this transition are either not preserved or have not yet been recognized.

\section{Fossils and the Emergence of Deuterostome Phyla}

\section{Carpoids and the Evolution of Echinoderms}

There have been precious few fossils identified as potential ancestors of each of the main deuterostome phyla — chordates, 
hemichordates, and echinoderms - in large part because the evolutionary relationships and number of deuterostome phyla has been an open question until relatively recently. However, the carpoids, a bizarre grouping of symmetrically and asymmetrically stalked animals with a calcitic echinodermlike skeleton (known as stereom) have been promoted as ancestors of all the deuterostome phyla, even including early representatives of the tunicate, cephalochordate, and vertebrate lineages of chordates (Jefferies et al. 1996). The debate over the affinities of carpoids is complex and involved, and we cannot do justice to the alternative scientific hypotheses here except to say that there are at least three opposing interpretations of their anatomy and, consequently, their evolutionary affinity. However, except for a small number of diehards, a consensus has recently emerged which indentifies the carpoids as the remnants of an extinct evolutionary lineage of early echinoderms. Like the gnathostome example above, analysis of the characters that indicate the degree of relationship between carpoids and echinoderms also reveals the sequence in which echinoderm characters were assembled in the early evolutionary history of the lineage. Surprisingly, the regular fivefold symmetry, so characteristic of echinoderms, evolved from some rather unlikely looking ancestors.

The precise interrelationships of the carpoids remain unclear, but Fig. 4 shows the broad pattern of echinoderm
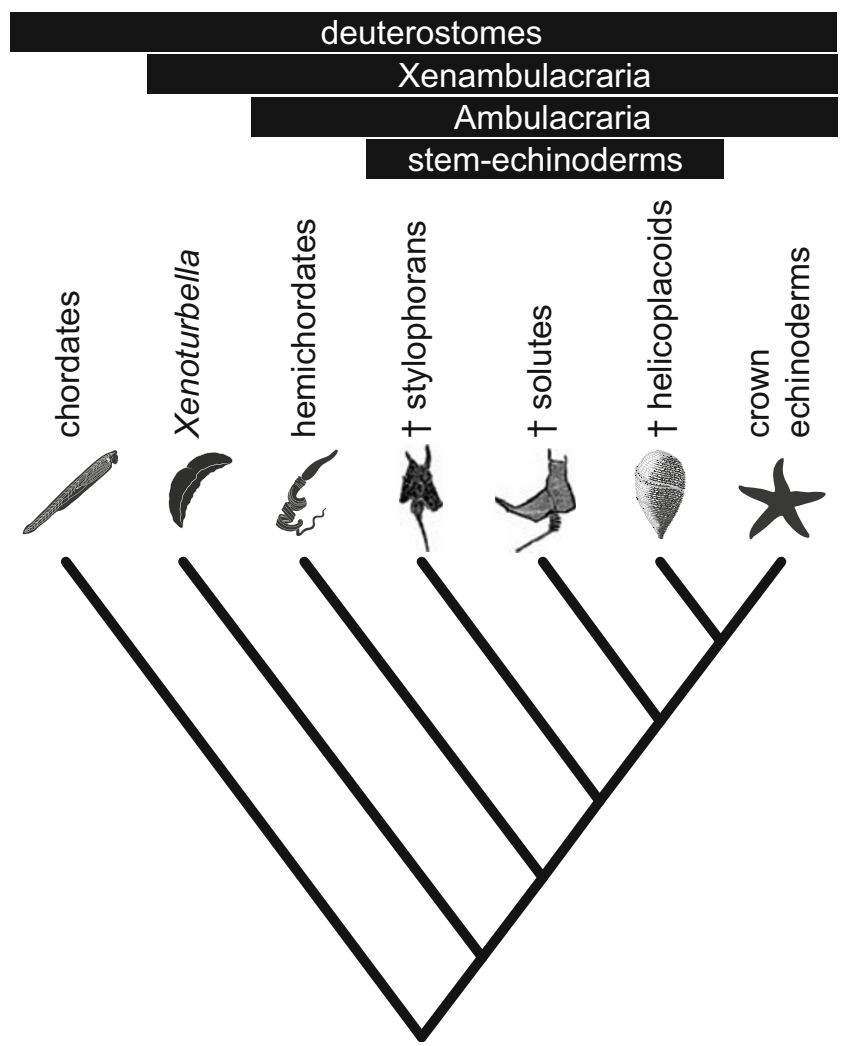

Fig. 4 The interrelationships of living and fossil echinoderms within the context of Deuterostomia. Primarily based upon Smith (2005, 2008) and Bourlat et al. (2008) relationships. Helicoplacoids, spindle-shaped animals with threefold rather than fivefold symmetry, are the closest relatives of the living echinoderms. They had an echinoderm-like water vascular system (the hydraulic system which functions in echinoderm respiration, locomotion, and transport of food and waste) and a calcitic stereom skeleton. The position of the helicoplacoid mouth, to one side of the animal, with the anus at one end, indicates that this important axis has shifted away from being front to back and was more echinoderm-like than all earlier members of the lineage (Smith 2008). Of the features most recognizable and characteristic of the echinoderm body plan, only pentaradial symmetry is lacking.

Moving further down the tree, solutes branch off, then stylophorans (cornutes and mitrates), then perhaps the cinctans (not shown). All these groups show evidence of an echinoderm-like water vascular system, retain a distinct anterior-posterior body axis, and possess an echinodermlike stereom skeleton. There is a trend of decreasing body symmetry through the lineage, from near bilateral symmetry of solutes to the strongly asymmetric stylophorans and cinctans. At some point after stylophorans branched off but before the first solutes, the gill slits, inherited by all previous members of the lineage from their basal deuterostome ancestors, were lost. Both groups of stylophorans preserve evidence of this primitive character (Dominguez et al. 2002; Jefferies 1973). Presumably, there were even earlier offshoots from this lineage linking echinoderms to the common ancestor they shared with hemichordates, but the likelihood of their being fossilized was very low because they had not yet evolved the mineralized calcitic stereom skeleton, and after death they will have rotted away without trace.

\section{The Origins of Other Deuterostome Phyla and the Limitations of the Fossil Record}

Untangling the riddle of carpoids has been a success story in elucidating the evolutionary assembly of the echinoderm body plan, but it tells us nothing about the evolutionary origins of the ambulacrarian, hemichordate, chordate, tunicate, cephalochordate, and vertebrate lineages. Fossil evidence of the emergence of these lineages and the assembly of the body plans characteristic of the living members of these lineages must be sought elsewhere, but there are precious few data to address these questions because there are very few other candidate fossil representatives of early deuterostomes, and most of those are difficult to interpret. Many are identified as primitive animals because they possess only primitive anatomical features, but it is often the case in such fossils that these are the only features to survive the process of fossilization, and it is difficult to determine whether the characters that would 
indicate a position higher in a tree are absent because they were never present or merely because they rotted away (Donoghue and Purnell 2009). Thus, various fossil organisms, such as the yunnanozoans (including Haikouella), have been interpreted as primitive deuterostomes (Shu et al. 2003b), primitive ambulacrarians (Shu et al. 2004), or as primitive chordates (Shu et al. 2004) because they seem to possess those few necessary characteristics, such as gill slits. Other features of the fossils, however, are difficult to interpret unequivocally (Mallatt et al. 2003; Shu and Morris 2003) and are taken by some to indicate links with hemichordates (Shu et al. 1996b) or vertebrates (Donoghue and Purnell 2009; Mallatt and Chen 2003). The same may be true of that icon of chordate evolution, Pikaia. Detailed study of the fossils continues (Shu et al. 1996a), but it may never be possible to resolve exactly where in the deuterostome tree it sits relative to the common ancestor of amphioxus and all other chordates.

It is unfortunate that the fossil record is almost silent on the question of the origins of the deuterostomes, the ambulacrarians, hemichordates, and the chordates, but the examples of the gnathostomes and the echinoderms show that major clades emerged through the gradual assembly of the characteristics that distinguish the living members of one phylum from another. Examples of the assembly of phylum level body plans are, however, very rare. In general, much of the early evolution of most phyla, obviously critical for reconstructing the sequence of body plan assembly, occurs before the acquisition of a mineralized skeleton. It is precisely because echinoderms evolved their calcitic skeleton at a point in time before the majority of echinodermspecific characters had emerged that we are able to reconstruct how they acquired their distinctive features. The fossil record of chordate evolution communicates a similar message: only after the evolution of the phosphatic skeleton in the lineage leading to gnathostomes do the fossils provide a reliable account of character acquisition. We will never know how many important, abundant, and diverse nonskeletonized deuterostomes have left no trace in the fossil record. The important point to take from this, however, is not that the fossil record is useless - it certainly is not-but that it cannot provide the same amount or quality of evolutionary data for all groups of organisms and, for lineages which lack preservable skeletal tissues, the record will inevitably be less good. For major groups that have mineralized skeletons, such as gnathostomes, however, the pattern that emerges from the analysis of the fossil record is clear: body plans are assembled incrementally, over millions of years, not in sudden bursts of irreducible complexity.

Acknowledgements Many thanks to Don Prothero for the invitation to contribute to this issue of Evolution: Outreach and Education. Simon Powell (Bristol) produced the images of animals used in the artwork. Greg Edgecombe provided an informative critique on the manuscript that resulted in an improved final version. We acknowledge funding from the National Endowment for Science, Technology, and the Arts (PCJD), The Leverhulme Trust (PCJD), the Biotechnology and Biological Sciences Research Council (PCJD), the European Union Framework 7 (PCJD), and the Natural Environment Research Council (PCJD; MAP).

\section{References}

Angielczyk, K. D. Dimetrodon is not a dinosaur: using tree thinking to understand the ancient relatives of mammals and their evolution. Evolution: Education \& Outreach. in press.

Bardack D. First fossil hagfish (Myxinoidea): a record from the Pennsylvanian of Illinois. Science. 1991;254:701-3.

Bardack D, Richardson ES Jr. New agnathous fishes from the Pennsylvanian of Illinois. Fieldiana Geol. 1977;33:489-510.

Bardack D, Zangerl R. First fossil lamprey: a record from the Pennsylvanian of Illinois. Science. 1968;162:1265-7.

Bourlat SJ, Juliusdottir T, Lowe CJ, Freeman R, Aronowicz J, Kirschner $\mathrm{M}$, et al. Deuterostome phylogeny reveals monophyletic chordates and the new phylum Xenoturbellida. Nature. 2006;444:85-8.

Bourlat SJ, Nielsen C, Economou AD, Telford MJ. Testing the new animal phylogeny: a phylum level molecular analysis of the animal kingdom. Mol Phylogen Evol. 2008;49:23-31.

Chang M-M, Zhang J, Miao DA. Lamprey from the Cretaceous Jehol biota of China. Nature. 2006;441:972-4.

Conway Morris S. A redescription of a rare chordate, Metaspriggina walcotti Simonetta and Insom, from the Burgess Shale (Middle Cambrian), British Columbia, Canada. J Paleontol. 2008;82:424 30.

Delarbre C, Barriel V, Janvier P, Gachelin G. Complete mitochondrial DNA of the hagfish, Eptatretus burgeri: the comparative analysis of mitochondrial DNA sequences strongly supports the cyclostome monophyly. Mol Phylogen Evol. 2002;22:184-92.

Delsuc F, Brinkmann H, Chourrout D, Philippe H. Tunicates and not cephalochordates are the closest living relatives of vertebrates. Nature. 2006;439:965-8.

Dominguez P, Jacobson AG, Jefferies RPS. Paired gill slits in a fossil with a calcite skeleton. Nature. 2002;417:841-4.

Donoghue PCJ, Purnell MA. Genome duplication, extinction and vertebrate evolution. Trends Ecol Evol. 2005;20:312-9.

Donoghue PCJ, Purnell MA. Distinguishing heat from light in debate over controversial fossils. BioEssays. 2009;31:178-89.

Donoghue PCJ, Smith MP. The anatomy of Turinia pagei (Powrie) and the phylogenetic status of the Thelodonti. Trans R Soc Edinb Earth Sci. 2001;92:15-37.

Donoghue PCJ, Forey PL, Aldridge RJ. Conodont affinity and chordate phylogeny. Biol Rev. 2000;75:191-251.

Donoghue PCJ, Graham A, Kelsh RN. The origin and evolution of the neural crest. BioEssays. 2008;30:530-41.

Dunn CW, Hejnol A, Matus DQ, Pang K, Browne WE, Smith SA, et al. Broad phylogenomic sampling improves resolution of the animal tree of life. Nature. 2008;452:745-9.

Forey PL. Agnathans recent and fossil, and the origin of jawed vertebrates. Rev Fish Biol Fisheries. 1995;5:267-303.

Gans C, Northcutt RG. Neural crest and the origin of the vertebrates: a new head. Science. 1983;220:268-74.

Gee H. Before the backbone: views on the origin of the vertebrates. London: Chapman \& Hall; 1996.

Gess RW, Coates MI, Rubidge BS. A lamprey from the Devonian period of South Africa. Nature. 2006;443:981-4.

Heimberg AM, Sempere LF, Moy VN, Donoghue PCJ, Peterson KJ. MicroRNAs and the advent of vertebrate morphological complexity. Proc Natl Acad Sci U S A. 2008;105:2946-50. 
Holland PWH, Garcia-Fernandez J, Williams NA, Sidow A. Gene duplications and the origins of vertebrate development. Development. 1994;1994 Supplement:125-33.

Huxley-Jones J, Robertson DL, Boot-Handford RP. On the origins of the extracellular matrix in vertebrates. Matrix Biol. 2007;26:2-11.

Janvier P. The phylogeny of the Craniata, with particular reference to the significance of fossil "agnathans". J Vertebr Paleontol. 1981;1: $121-59$.

Janvier P. The dawn of the vertebrates: characters versus common ascent in the rise of current vertebrate phylogenies. Palaeontology. 1996;39:259-87.

Janvier P. Ostracoderms and the shaping of the gnathostome characters. In: Ahlberg PE, editor. Major events in early vertebrate evolution: palaeontology, phylogeny, genetics and development. London: Taylor and Francis; 2001. p. 172-86.

Janvier P, Lund R. Hardistiella montanensis n. gen. et sp. (Petromyzontida) from the Lower Carboniferous of Montana, with remarks on the affinities of lampreys. J Vertebr Paleontol. 1983;2:407-13.

Jefferies RPS. The Ordovician fossil Lagynocystis pyramidalis (Barrande) and the ancestry of amphioxus. Philos Trans R Soc Lond Series B. 1973;265:409-69.

Jefferies RPS, Brown NA, Daley PEJ. The early phylogeny of chordates and echinoderms and the origin of chordate left-right asymmetry and bilateral symmetry. Acta Zool (Stockh). 1996; 77:101-22.

Jeffery WR. Ascidian neural crest-like cells: phylogenetic distribution, relationship to larval complexity, and pigment cell fate. J Exp Zool B Mol Dev Evol. 2006;306B:470-80.

Jeffery WR, Strickler AG, Yamamoto Y. Migratory neural crest-like cells form body pigment in a urochordate embryo. Nature. 2004; 431:696-9.

Jenner RA. When molecules and morphology clash: reconciling conflicting phylogenies of the Metazoa by considering secondary character loss. Evol Dev. 2004;6:372-8.

Jenner RA, Schram FR. The grand game of metazoan phylogeny: rules and strategies. Biol Rev. 1999;74:121-42.

Kemp TS. The origin of higher taxa: macroevolutionary processes, and the case of the mammals. Acta Zoologica. 2007;88:3-22.

Lartillot N, Philippe H. Improvement of molecular phylogenetic inference and the phylogeny of Bilateria. Philos Trans Royal Soc B Biol Sci. 2008;363:1463-72.

Le Douarin NM, Kalcheim C. The neural crest. Cambridge: Cambridge University Press; 1999.

Løvtrup S. The phylogeny of the Vertebrata. New York: Wiley; 1977.

Mallatt J, Chen J-Y. Fossil sister group of craniates: predicted and found. J Morphol. 2003;258:1-31.

Mallatt J, Winchell CJ. Ribosomal RNA genes and deuterostome phylogeny revisited: more cyclostomes, elasmobranchs, reptiles, and a brittle star. Mol Phylogen Evol. 2007;43:1005-22.

Mallatt J, Chen JY, Holland ND. Comment on "A new species of yunnanozoan with implications for deuterostome evolution". Science. 2003;300:1372.
Martinez-Morales JR, Henrich T, Ramialison M, Wittbrodt J. New genes in the evolution of the neural crest differentiation program. Genome Biology. 2007;8(R36).

Mazet F, Hutt JA, Milloz J, Millard J, Graham A, Shimeld SM. Molecular evidence from Ciona intestinalis for the evolutionary origin of vertebrate sensory placodes. Dev Biol. 2005;282:494-508.

McLennan D. The concept of co-option: why evolution often looks miraculous. Evo Edu Outreach. 2008;1:247-58.

Meyer SC. The origin of biological information and the higher taxonomic categories. Proc Biol Soc Wash. 2004a;117:213-39.

Meyer SC. The Cambrian information explosion: evidence for intelligent design. In: Dembski WA, Ruse M, editors. Debating design: from Darwin to DNA. Cambridge: Cambridge University Press; 2004b. p. 371-91.

Padian K, Chiappe LM. The origin and early evolution of birds. Biol Rev. 1998;73:1-42.

Prohaska SJ, Stadler PF. The duplication of the Hox gene clusters in teleost fishes. Theory Biosci. 2004;123:89-110.

Raineri M. Are protochordates chordates? Biol J Linn Soc. 2006; $87: 261-84$.

Shu D-G. A paleontological perspective of vertebrate origin. Chin Sci Bull. 2003;48:725-35.

Shu D-G, Conway Morris S. Response to comment on "A new species of Yunnanozoon with implications for deuterostome evolution". Science. 2003;300:1372d.

Shu D-G, Conway Morris S, Zhang X-L. A Pikaia-like chordate from the Lower Cambrian of China. Nature. 1996a;384:157-8.

Shu D-G, Zhang X, Chen L. Reinterpretation of Yunnanozoon as the earliest known hemichordate. Nature. 1996b;380:428-30.

Shu D-G, Luo H-L, Conway Morris S, Zhang X-L, Hu S-X, Chen L, et al. Lower Cambrian vertebrates from south China. Nature. 1999;402:42-6.

Shu D-G, Conway Morris S, Han J, Zhang Z-F, Yasui K, Janvier P, et al. Head and backbone of the Early Cambrian vertebrate Haikouichthys. Nature. 2003a;421:526-9.

Shu D-G, Conway Morris S, Zhang ZF, Liu JN, Han J, Chen L, et al. A new species of Yunnanozoon with implications for deuterostome evolution. Science. 2003b;299:1380-4.

Shu D-G, Conway Morris S, Han J, Zhang Z-F, Liu J-N. Ancestral echinoderms from the Chengjiang deposits of China. Nature. 2004;430:422-8.

Sidow A. Gen(om)e duplications in the evolution of early vertebrates. Curr Opin Genet Dev. 1996;6:715-22.

Smith AB. The pre-radial history of echinoderms. Geol J. 2005;40: 255-80.

Smith AB. Deuterostomes in a twist: the origins of a radical new body plan. Evolut Develop. 2008;10:493-503.

Sweet WC, Donoghue PCJ. Conodonts: past, present and future. J Paleontol. 2001;75:1174-84.

Wagner GP, Amemiya C, Ruddle F. Hox cluster duplications and the opportunity for evolutionary novelties. Proc Natl Acad Sci U S A. 2003;100:14603-6. 